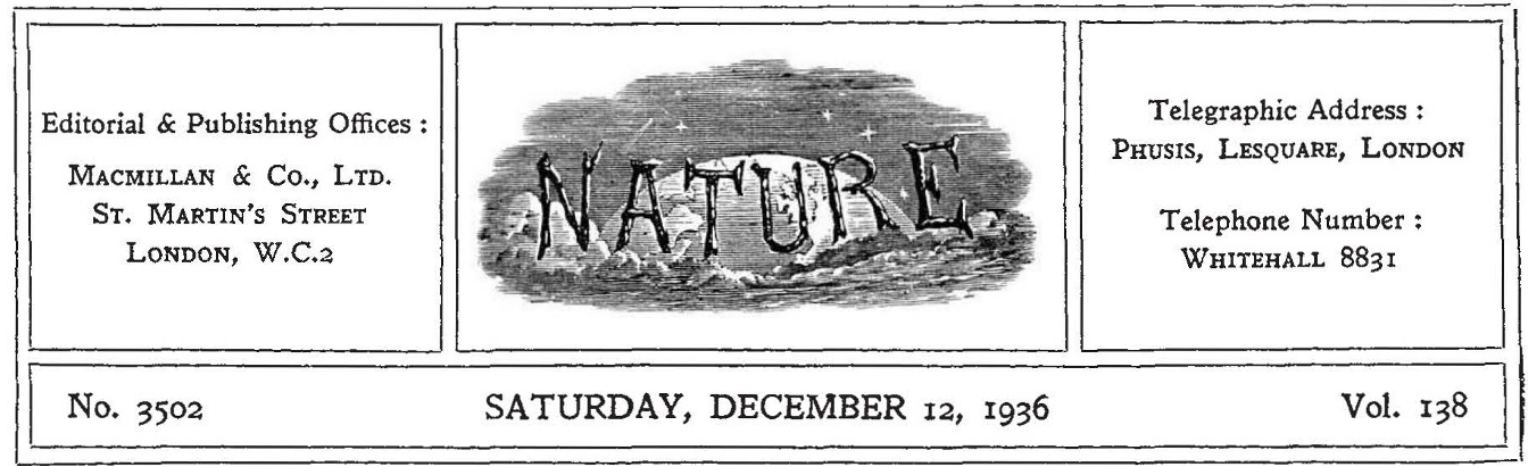

\title{
Armaments and the Scientific Worker
}

$T$ HE recently issued report* of the Royal Commission, which has dealt with the private manufacture and sale of munitions of war, contains a number of special points of particular interest to the scientific worker. A considerable amount of evidence was laid before the Commission designed to show that the manufacture of armaments should be concentrated in Government hands to promote the development of research, design and invention. It was argued that centralization of research work under unified control prevents dissipation of effort and that closer contact is possible between research and experimental work in Government stations, which have greater facilities than private establishments for experiment. Similarly, it was urged that money is more readily available for research in Government establish ments, where there is not the necessity to visualize a prospect of dividend on capital that there is with private enterprise, as well as the danger of prejudicing the interests of the State if a private manufacturer does not develop a new invention which may not be to his own advantage, the motive of profit-making in certain circumstances tending to retard the development of new ideas.

Other evidence brought before the Commission denied that the development of research, design and invention in the matter of armaments would be facilitated by nationalization. It was stated that research work is cramped within Government departments, and that in peace time funds for research are more readily made available by private industry than by the Government. It was also argued that the supply of war material by Government establishments alone would result in sound but mediocre material because the

- Royal Commission on the Private Manufacture of and Trading in Arms (1935-36): Report. (Cmd. 5292.) Pp. 101. (London: H.M Stationery Office, 1936.) $1 s$. $6 d$. net. atmosphere and conditions of Government service do not favour the development of new ideas. Moreover, since discovery, research and development of new ideas result from individual effort, they do not lend themselves to centralized organization, and Government employees do not seek to assume additional responsibilities or incur the risk of putting forward new ideas which may be regarded as impracticable in high quarters. Not only does competition under private manufacture provide a strong incentive to individuals to find new and improved devices, but also research conducted by commercial undertakings in nonmilitary matters is just as likely to result in discoveries of military value, the tank itself being cited as an idea which emanated from a private engineering firm.

The report itself makes no pronouncement either upon the separate aspect of the case of the opponents of private manufacture based upon its alleged inefficiency and the lack of opportunity for fully developed research, or upon the counter arguments in this matter of the supporters of the present system. Neither side refers to the ethical questions of the participation of men of science in preparations for war or the possible formulation of a professional code of ethics which at the present time is seriously occupying the minds of scientific workers whose participation is essential under either system of control. None the less, this is probably the most important aspect so far as the stimulation of invention and discovery is concerned.

Disgust and dissatisfaction at the prostitution of scientific effort to the elaboration of even more destructive weapons is now too widespread to be disregarded. Any system, whether national or international, which encourages unlimited misuse 
in this way can scarcely long escape repudiation and overthrow. While scientific workers are of no two minds as to the necessity for whatever armaments we must have being efficiently produced and maintained, they would find a very considerable support for opposition to any system which demanded their efforts in the development of offensive, as opposed to defensive, weapons indefinitely. Moreover, the scientific worker in matters of national defence should require no further stimulus than his specific occupation if those ethical needs are satisfied. If, on the other hand, they are left unsatisfied, it is doubtful whether any system of armaments manufacture can supply a stimulus as effective.
The report of the Royal Commission accordingly will be something of a disappointment to those scientific workers who are concerned with the ethical aspects of their participation in the preparations for national defence. It gives no lead on certain of these questions of research and development which, apart from the ethical aspect, are equally to be encountered in other fields of industrial and scientific research. At least, however, it emphasizes once more that the task of constructing world peace involves not merely the abolition of war, but also the far-reaching and impartial study of all its many causes, and not least that of the contribution and organization of the armaments industry itself.

\section{Genetics and Race}

IN the classificatory systems of a number of sciences the term 'race' occurs. Its meaning differs somewhat from science to science, but in all it has two main connotations, one being community of descent, the other distinctness from other races. Years ago the term signified something rather definite, but as time has passed and knowledge has advanced, this has given place to something much more vague. In general biology, for example, 'race' has now been largely abandoned in favour of 'sub-species'-a term much more in harmony with the concept that it is used to portray.

So long as the definition of race in the usage of one science does not invade the territory of another, it is a matter of no great importance if there are as many definitions as there are sciences ; but if and when the term race as used by the physical anthropologists, for example, comes to have genetical implications, then it is reasonable for the geneticist to express the view that the anthropologists' definition must neither disregard nor offend genetic principles. This it does, for the anthropological use of the term dates from the time when it was believed that organic inheritance was of the blending variety, so that a mixed population would speedily approximate to a characteristic uniform type. This assumption has been shown to be incorrect by the establishment of the Mendelian basis of inheritance, and it is now known that constellations of characters necessarily become broken up and their ingredients shifted back and forth, combined and recombined, when, consequent upon the removal of isolation and inbreeding, crossing occurs. Furthermore, the assumption that man's evolution has taken the form of a separation into discreet isolated units is also incorrect, since migration and crossing have been operative for tens of thousands of years, so that, whereas the evolution of most animal types is divergent, that of man has been what may be called reticulate.

This was the reason for a joint meeting on September 11 of Sections H (Anthropology) and D (Zoology) of the British Association at Blackpool, at which the speakers were primarily concerning themselves with the question of whether or not the anthropologist's definition of race required modification in consequence of recent developments in genetics. But no one at this crowded meeting was unaware that the speakers were indirectly commenting upon the exploitation of the race concept by politicians who apparently are deliberately confusing linguistic terms such as 'Aryan', cultural terms such as 'germanic' and genetic terms like 'Nordic' by using them synonymously. It undoubtedly is the case that the term 'race' is now being used in a pseudo-scientific sense to further purely political interests, and this being so, it behoves all scientific workersanthropologists, ethnologists and the rest-to respond to the demand on the part of the general public for guidance concerning the quality of the pronouncements of those who claim scientific 